\title{
Variation in Formulary Management Practices Within the Department of Veterans Affairs Health Care System
}

\author{
Thomas R. Radomski, MD; Chester B. Good, MD, MPH; Carolyn T. Thorpe, PhD, MPH; \\ Xinhua Zhao, PhD; Zachary A. Marcum, PharmD, PhD; Peter A. Glassman, MBBS; \\ John Lowe, MBA; Maria K. Mor, PhD; Michael J. Fine, MD, MSc; and Walid F. Gellad, MD, MPH
}

\begin{abstract}
BACKGROUND: All Department of Veterans Affairs Medical Centers (VAMCs) operate under a single national drug formulary, yet substantial variation in prescribing and spending exists across facilities. Local management of the national formulary may differ across VAMCs and may be one cause of this variation.
\end{abstract}

OBJECTIVE: To characterize variation in the management of nonformulary medication requests and pharmacy and therapeutics (P\&T) committee member perceptions of the formulary environment at VAMCs nationwide.

METHODS: We performed an online survey of the chief of pharmacy and an additional staff pharmacist and physician on the P\&T committee at all VAMCs. Respondents were asked questions regarding criteria for use for nonformulary medications, specific procedures for ordering nonformulary medications in general and specific lipid-lowering and diabetes agents, the appeals process, and the formulary environment at their VAMCs. We compared responses across facilities and between chiefs of pharmacy, pharmacists, and physicians.

RESULTS: A total of 212 chief pharmacists $(n=80)$, staff pharmacists $(n=78)$, and physicians $(n=54)$ responded, for an overall response rate of $49 \%$. In total, $107 / 143(75 \%)$ different VAMCs were represented. The majority of VAMCs reported adhering to national criteria for use, with 38 $(36 \%)$ being very adherent and $69(65 \%)$ being mostly adherent. There was substantial variation between VAMCs regarding how nonformulary drugs were ordered, evaluated, and appealed. The nonformulary lipid-lowering drugs ezetimibe, rosuvastatin, and atorvastatin were viewable to providers in the order entry screen at 67 (63\%), 67 (63\%), and 64 (60\%) VAMCs, respectively. The nonformulary diabetes medication pioglitazone was only viewable at $58(55 \%)$ VAMCs. In the remaining VAMCs, providers could not order these nonformulary drugs through the normal order-entry process. For questions about the formulary environment, physician respondent perceptions differed from those of staff pharmacists and chief pharmacists. Compared with pharmacy chiefs and staff pharmacists, physicians were less likely to agree that providers at their VAMC prescribed too many nonformulary medications ( $47 \%$ and $44 \%$ vs. $12 \%, P<0.001$ ), more likely to agree that providers must jump through too many hoops to prescribe nonformulary medication ( $5 \%$ and $3 \%$ vs. $25 \%, P<0.001$ ), and more likely to agree that providers make an effort to convert new patients from nonformulary to formulary lipid-lowering $(65 \%$ and $73 \%$ vs. $94 \%, P<0.02)$ and diabetic medications ( $49 \%$ and $50 \%$ vs. $88 \%, P<0.001)$.

CONCLUSIONS: Although the Department of Veterans Affairs (VA) operates under a single national formulary, we found significant differences among VAMCs regarding their management of nonformulary medication requests. We also found differences among formulary leaders regarding their perception of the environment in which their VAMC's formulary is managed. These findings have important implications not just for VA, but for any organization that develops, implements, and manages drug formularies across multiple facilities.

J Manag Care Spec Pharm. 2016;22(2):114-20

Copyright $\odot 2016$, Academy of Managed Care Pharmacy. All rights reserved.

\section{What is already known about this subject}

There is substantial variation in prescribing practices across Department of Veterans Affairs Medical Centers (VAMCs) despite operating under a national formulary.

The use of nonformulary medications is regulated by the pharmacy and therapeutics (P\&T) committee at each VAMC rather than nationally.

The processes and atmosphere under which a P\&T committee manages its formulary, known as the formulary environment, influence the quality and consistency of its work and may influence the use of nonformulary medications.

\section{What this study adds}

There was substantial variation among VAMCs regarding how nonformulary medications were ordered, evaluated, and appealed. Physicians differed from staff pharmacists and pharmacy chiefs in their perceptions of the formulary environment at their VAMC. These differences likely contributed to the variations in prescribing practices observed within the Department of Veterans Affairs and may serve as an important lesson for any health care organization tasked with managing a drug formulary.

$\square$ rug formulary management is an important tool to control pharmacy costs and ensure safe and effective prescribing practices. ${ }^{1}$ Strategies such as designating preferred formulary drugs, prior authorization, therapeutic substitution, and encouraging the use of generic medications are all key components of formulary management. ${ }^{2-9}$ The Department of Veterans Affairs (VA) created its national drug formulary in $1997^{10}$ with the goal of unifying the local VA formularies in existence at that time. ${ }^{11}$ Since then, this system has saved VA billions of dollars in drug expenditures and ensured high-quality medical care by using these formulary management strategies. ${ }^{10,12-14}$

Despite VA operating under a uniform formulary, there is substantial variation in drug spending and prescribing practices at the local and regional levels throughout VA. Prior studies have shown that the use of brand-name drugs varies widely throughout VA, ${ }^{15-17}$ as does the use of potentially dangerous anticholinergics and benzodiazepines. ${ }^{18}$ These differences have been shown to impact both health care costs and quality. ${ }^{15-19}$ 
Although each VA Medical Center (VAMC) has unique characteristics that impact drug use and spending, such as its patient mix, provider mix, and academic affiliation, the dayto-day implementation of the VA national formulary may also impact drug use differently across VAMCs. For example, the use of nonformulary medications is generally regulated by the pharmacy and therapeutics (P\&T) committee at each VAMC rather than nationally. ${ }^{20}$ It has been shown at non-VA medical centers that the processes and atmosphere under which a P\&T committee manages its formulary, known as the formulary environment, influence the quality and consistency of the P\&T committee's work. ${ }^{21,22}$ Implementation of the national VA formulary at the local level may allow these same factors to operate within the VA health care system. No prior studies have examined how formulary management practices vary across VAMCs and how these variations affect the ordering, evaluation, and appeal of nonformulary medication.

The objective of this study was to characterize variations in drug formulary management and the environment in which P\&T committees operate throughout VA, using a national survey of formulary leaders at each VAMC. The first goal of the study was to better understand how local VA P\&T committees implement the national drug formulary. A second goal was to examine whether perceptions of the VA national formulary varied by provider type (i.e., pharmacists vs. physicians). In addition to informing improvements to the formulary management process across VA, the results should also inform non-VA health insurance plans or health care systems tasked with the challenge of managing their own formularies or pharmacy benefits package.

\section{Methods}

\section{Study Population and Data Collection}

We contacted the chiefs of pharmacy at each VAMC across the country (143 facilities) to inform them about the survey and ask for the contact information for 2 additional survey participants: 1 pharmacist and 1 medical doctor who serve on the P\&T committee at their VAMC. These 3 individuals at each VAMC served as the potential survey respondents.

The contact information for each individual was provided to VA's Health Care Talent Management Office, an independent survey group within VA, for online distribution of the survey over a 1-month period in July 2011. Respondents who did not initially complete the survey were sent up to 3 follow-up automated e-mail reminders. All survey responses were deidentified, and each VAMC received a unique study ID to maintain confidentiality. All study procedures were approved by the institutional review board at the VA Pittsburgh Healthcare System.

\section{Survey Instrument}

To develop the formulary survey questions, we reviewed the literature and queried individuals on the study team familiar with VA pharmacy benefit management (PBM) formulary processes. Three study authors with extensive national VA PBM experience were actively involved in designing the survey. After drafting the survey instrument, we solicited detailed feedback from 2 former chiefs of pharmacy on overall survey comprehensiveness, accuracy, and ease of use. The survey focused on 4 domains: criteria for use (CFU), specific procedures for nonformulary medication requests, the appeals process for rejected nonformulary requests, and the formulary environment. Survey items and response options are shown in the Appendix (available in online article).

The first section asked respondents how VA CFU are applied at their institutions. CFU are guidelines set forth by the PBM for the safe and effective use of selected formulary and nonformulary medications. Respondents were asked whether their medical center routinely used national CFU, how frequently they modified the CFU, and how adherent they were to the national CFU on the whole.

The second section asked about the specific procedures used for handling requests for nonformulary medications. This section focused on who the main decision makers were for nonformulary requests and the manner in which nonformulary drugs were ordered through the Computerized Patient Record System (CPRS), VA's electronic health record. Being able to view a nonformulary medication in CPRS enables providers to find such a medication in the order entry screen similarly to how they would find a formulary medication, thereby facilitating the ordering process. At some VAMCs, providers are only required to enter the nonformulary medication into CPRS. At others, providers must either fill out a self-approval template or submit a general or drug-specific nonformulary consult in CPRS prior to the medication being approved. Questions were asked about nonformulary medications in general, as well as about the specific nonformulary medications (as of July 2011) ezetimibe, atorvastatin, rosuvastatin, and pioglitazone. These medications were restricted on VA's formulary at the time of this study and have previously been shown to be prescribed at differing frequencies throughout VA. ${ }^{15-17}$

The third section focused on the appeals process governing rejected nonformulary medication requests and the support of upper management regarding this process.

The fourth section assessed the formulary environment. ${ }^{21}$ Respondents were asked, using a 5-point Likert scale, the extent to which they agreed or disagreed with statements such as "It is important that providers adhere to formulary prescribing guidelines" and "Formulary restrictions make clinicians jump through too many hoops" (see Appendix for additional questions).

\section{Data Analyses}

Our first set of analyses were focused on describing variation in how local VAMCs implement the national drug formulary and were conducted at the facility-level using data from 
1 key informant per VAMC. When available, chief of pharmacy respondents were used as the key informant, given the chief's responsibility over formulary management at each VAMC. For VAMCs where the chief of pharmacy did not respond, the pharmacist on the P\&T committee was used instead. VAMCs for which only physicians responded $(n=7)$ were excluded from the facility-level analyses. For each item of interest, we calculated the frequency and percentages of responses, combining adjacent frequency categories when appropriate.

Our second set of analyses examined whether perceptions of the VA national formulary varied by provider type. In order to control for facility effect, overall comparisons between all provider types and pairwise comparisons between specific provider types (i.e., physician vs. staff pharmacist) were performed using a modified Mantel-Haenszel procedure allowing a combination of matched and unmatched data. ${ }^{23}$ A sensitivity analysis including only those sites with 2 or more respondents was performed using the standard Cochran-Mantel-Haenszel test. A 2-tailed $P$ value of $<0.05$ was considered statistically significant.

\section{Results}

\section{Respondent Characteristics}

Out of the 429 surveys sent, there were 212 respondents, including chiefs of pharmacy, staff pharmacists, and physicians, for an individual response rate of $49 \%$. Given our use of deidentified responses, we were not able to compare the characteristics of respondents and nonrespondents. Of the 212 respondents, 80 (38\%) identified themselves as the chief of pharmacy at their institution, 78 (37\%) identified themselves as a staff pharmacist, and 54 (25\%) identified themselves as a physician. In total, 107 different VAMCs were represented by at least 1 pharmacist respondent, accounting for $75 \%$ of all 143 VAMCs surveyed. Of these 107 VAMCs, 80 (75\%) included a chief of pharmacy response, and the remaining 27 (25\%) were based upon the response of a staff pharmacist.

\section{Facility-Level Responses}

Of the 107 VAMCs, 106 (99\%) reported routinely using the national CFU when assessing nonformulary drug requests. When asked about their adherence to the national CFU, 38 (36\%) reported being very adherent (defined as following "the letter of the law" regarding their adherence to the national CFU) and 69 (65\%) reported being mostly adherent. Overall, 76 VAMCs (72\%) reported never modifying the national CFU for local use, 24 (22\%) did modify the national CFU, and 6 (6\%) were unsure. Of the 24 VAMCs (22\%) that did modify the national CFU for local use, 14 (13\%) modified the national CFU only 1 to 2 times per year, whereas 10 (9\%) reported 3-10 modifications per year. When national CFU were not available, only 31 (29\%) VAMCs reported always developing their own locally.

In almost all instances, decisions about adjudicating nonformulary medication requests were made at the individual
VAMC level ( $\mathrm{n}=105,98 \%)$; only 2 VAMCs reported adjudication at the Veterans Integrated Service Network level. In 104 (97\%) VAMCs, a pharmacist or group of pharmacists was the initial evaluator of nonformulary requests. Of the 91 VAMCs that indicated all the ways they assign pharmacists to review nonformulary requests, 45 (49\%) reported no specific way of making assignments, whereas 30 (33\%) assigned a pharmacist based on the drug class, 26 (29\%) considered the primary care clinic of the prescriber, and 31 (34\%) assigned a pharmacist based on the specialty clinic where the prescription originated. Certain nonformulary requests require additional clinical or cost consideration prior to making a final decision, as established at either the national or local VA level. When this was the case, 65 VAMCs (61\%) involved either the P\&T committee or a designated clinician, $55(51 \%)$ involved the chief or assistant chief of pharmacy, and 45 (42\%) involved the chief or assistant chief of staff in these decisions.

There was also variation regarding whether providers could view certain nonformulary medications when typed into the CPRS order-entry screen. The nonformulary lipid-lowering drugs ezetimibe and rosuvastatin were both viewable in CPRS at 67 (63\%) VAMCs and atorvastatin was viewable at 64 (60\%) VAMCs. The nonformulary diabetes medication pioglitazone was viewable in only 58 (55\%) VAMCs.

Table 1 depicts the specific process by which nonformulary lipid-lowering medications and pioglitazone were ordered at each VAMC. Lipid-lowering agents were most commonly ordered through a general nonformulary template/consult in the order entry system. These drugs could be typed directly into the order entry system without submitting a consult at $18(17 \%)$ to 22 (21\%) VAMCs, depending on the specific drug. Notably, at 8 (8\%) VAMCs, rosuvastatin was ordered solely through a self-approval template or checkbox.

Regarding the appeals process for denied nonformulary medication requests, 95 (89\%) VAMCs reported that 1\% to 9\% of denied requests were appealed, whereas the remaining 12 (11\%) reported an appeal rate of $10 \%$ or greater. When a denied nonformulary request was appealed, the P\&T committee or a designated clinician was responsible for the review at 52 (49\%) VAMCs, followed by the medical chief or assistant chief of staff at 52 (49\%) VAMCs. The chief or assistant chief of pharmacy was also responsible for reviewing appeals at 24 (22\%) VAMCs.

\section{Provider Perceptions of the Formulary Environment}

There was no significant difference in the proportion of chief pharmacists (98\%), staff pharmacists (100\%), and physicians (98\%) who agreed that formulary medications should be prescribed prior to making nonformulary requests $(P=0.34)$. Chief pharmacists (81\%), staff pharmacists (85\%), and physicians (85\%) also agreed that their VAMC's nonformulary process is effective in controlling costs $(P=0.81)$. A greater percentage of chief pharmacists (78\%) agreed that their VAMC has a 


\begin{tabular}{|c|c|c|c|c|}
\hline \multirow[b]{2}{*}{ Ordering Method } & \multicolumn{4}{|c|}{$\begin{array}{c}\text { Percentage of VAMCs Reporting Each Ordering Method for } \\
\text { Specific Nonformulary Drugs }(\mathrm{N}=107)\end{array}$} \\
\hline & Atorvastatin & Rosuvastatin & Ezetimibe & Pioglitazone \\
\hline Through a general nonformulary consult/template in CPRS & 52 & 43 & 52 & 41 \\
\hline Directly typed into the medication order entry screen in CPRS & 18 & 20 & 21 & 17 \\
\hline Through a self-approval based template/checkbox in CPRS & 2 & 8 & 0 & 2 \\
\hline Through drug-specific consult/template in CPRS & 24 & 25 & 23 & 36 \\
\hline Uncertain & 5 & 5 & 5 & 5 \\
\hline
\end{tabular}

local champion for cost-effective drug utilization than physicians $(61 \%, P=0.02)$ and staff pharmacists $(63 \%, P=0.096)$. Although the majority of respondents agreed that their VAMC's nonformulary approval process is effective in ensuring quality of care and safe drug use, only $75 \%$ of physicians agreed with this statement, compared with $89 \%$ of pharmacy chiefs $(P=0.03)$ and $91 \%$ of staff pharmacists $(P=0.02)$. A greater percentage of physicians (90\%) disagreed, as compared with chief pharmacists $(82 \%, P=0.12)$ and staff pharmacists $(69 \%$, $P=0.007$ ), that there is much variation between reviewers of nonformulary requests.

Physicians (12\%) were less likely to agree that providers at their VAMC prescribe too many nonformulary medications, compared with pharmacy chiefs $(47 \%, P<0.001)$ and staff pharmacists (44\%, $P<0.001$, Figure 1A). Physicians (25\%) were more likely to agree that nonformulary restrictions cause providers to jump through too many hoops, compared with chief pharmacists $(5 \%, P<0.001)$ and staff pharmacists $(3 \%$, $P<0.001$, Figure 1B). Physicians (94\%) were also more likely to agree that providers make an effort to switch new patients from nonformulary to formulary lipid-lowering medications, compared with staff pharmacists $(73 \%, P=0.02)$ and pharmacy chiefs $(65 \%, P=0.004$, Figure $1 C)$. When asked the same question about the drug pioglitazone, $88 \%$ of physicians agreed, whereas only $49 \%$ of pharmacy chiefs $(P<0.001)$ and $50 \%$ of staff pharmacists agreed $(P<0.001$, Figure 1D).

\section{Sensitivity Analysis}

A sensitivity analysis compared provider responses from those 76 (71\%) VAMCs where more than 1 provider responded. These included 47 (44\%) VAMCs where both a physician and either a chief pharmacist or staff pharmacist responded and 51 (48\%) VAMCs where both a chief pharmacist and staff pharmacist responded. We also observed statistically significant differences in perceptions of the formulary environment between provider types that were comparable to those observed in the overall analysis.

\section{Discussion}

Although VA operates under a single national formulary, we found significant variation between VAMCs regarding their management of nonformulary medication requests, including how drugs are ordered, evaluated, and appealed. We found variations in the nonformulary medications that were viewable to providers in the electronic order entry system, whether consults were required to access nonformulary medications, and if these consults needed to be medication specific or generic. We also discovered significant differences between provider types regarding their perceptions of the formulary environment and the prescribing of nonformulary medications at their VAMC. Our findings highlight important lessons not just for VA, but for any health care system or PBM that develops, implements, or manages a drug formulary.

Most importantly, our study shows that the presence of a national formulary does not ensure uniformity of formulary management at the local level, with likely significant impact on access to nonformulary medications. Although differences in physician preferences as well as differences in patient populations and practice settings might explain some variation in prescribing at the local and regional levels, differences in the application of the utilization management practices of the formulary are likely responsible for an important fraction of the variation in prescribing noted in previous studies. ${ }^{15-17}$ Local control over the nonformulary request process is not necessarily bad, because this control allows facilities to operate with greater flexibility to meet the unique needs of their patients. Nevertheless, it is possible that local control also enables the unnecessary prescribing of expensive brand-name drugs in some cases and needlessly limits the use of certain drugs in others.

Physicians, pharmacists, and pharmacy chiefs likely perceive the formulary environment at their facilities in different ways because of their different roles regarding nonformulary requests. These differences are in spite of the fact that each respondent is a member of the P\&T committee and responsible for the management of the formulary at their institution. For example, compared with pharmacists and pharmacy chiefs, 
A.Providers at your VAMC prescribe too many nonformulary drugs (i.e., more than clinically indicated in the setting of the VA formulary).

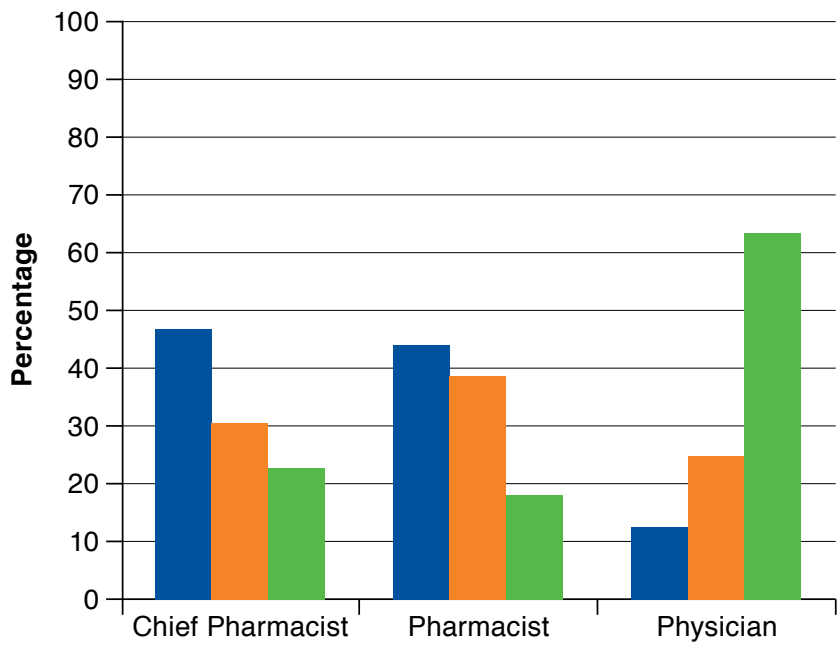

C. For new patients who come to your VAMC already receiving nonformulary lipid-lowering medications, providers usually make an effort to switch the patient to a formulary medication (if not contraindicated) prior to request of any nonformulary agents.

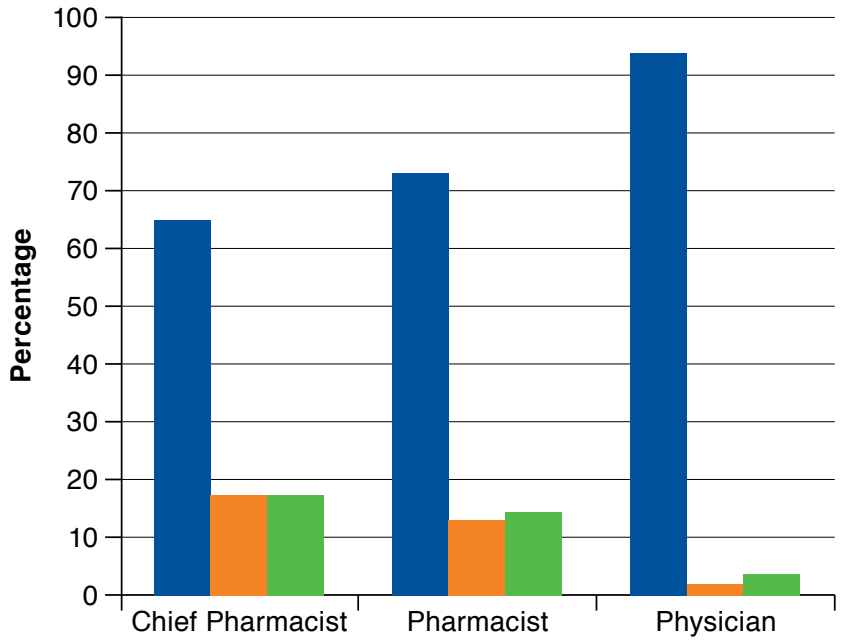

B. Nonformulary restrictions make providers jump through too many hoops to provide high-quality patient care.

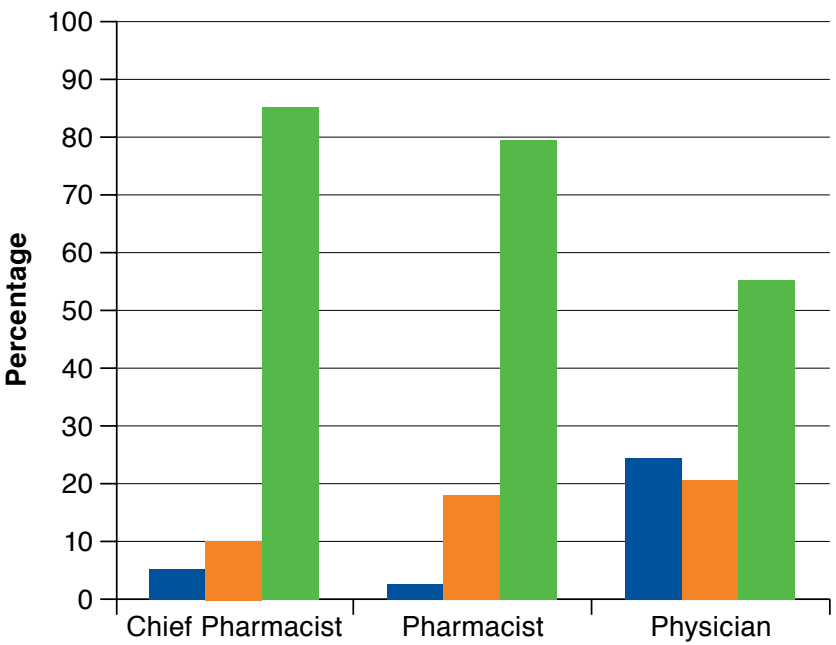

D. For new patients who come to your VAMC already receiving nonformulary TZDs, providers usually make an effort to switch the patient to a formulary medication (if not contraindicated) prior to request of any nonformulary agents.

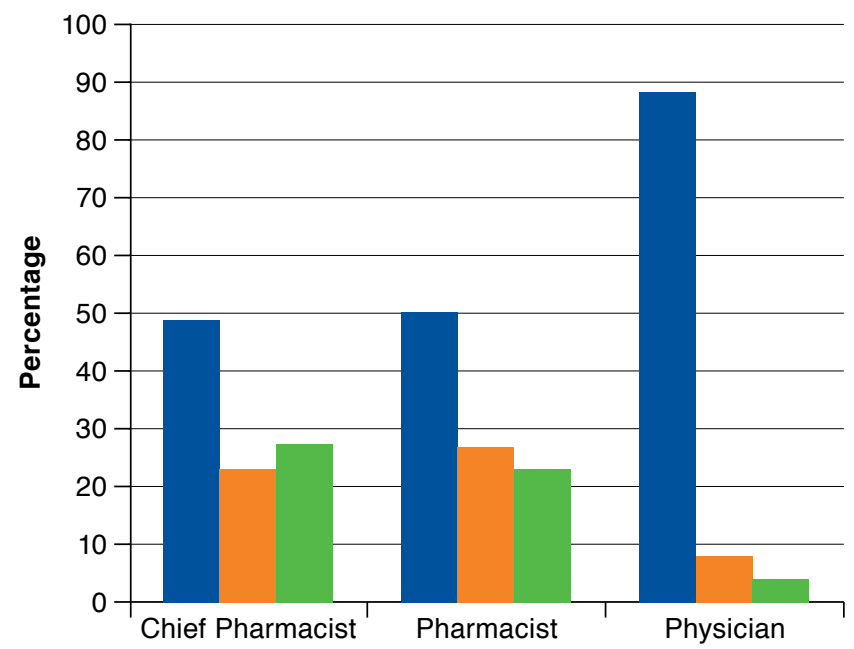

Strongly Agree or Agree $\quad$ Neutral Disagree or Strongly Disagree

aAll comparisons were statistically significant $(P<0.01)$.

TZD = thiazolidinedione; VA= Department of Veterans Affairs; VAMC= Department of Veterans Affairs Medical Center.

physicians were more likely to report that providers make an effort to convert new patients from nonformulary to formulary medications. This view likely reflects the time and effort physicians expend during a visit to switch a patient from a nonformulary to a formulary medication, regardless of whether their efforts are successful. A survey of more than 2,050 physicians across VA was conducted shortly after implementation of the national formulary. Although a majority had a generally positive view of the VA formulary, a significant minority (29\%) still reported that the formulary adversely impacted their 
ability to provide quality care to their patients and 34\% perceived the national formulary to have increased their work load. ${ }^{24}$ Additionally, pharmacists have been characterized as working in silos, focusing more on drug-acquisition costs and viewing medications as a product, rather than providing a comprehensive service that is aligned with the needs of other health care providers. ${ }^{25,26}$ This isolation may affect pharmacists' understanding of the point of view of physicians when adjudicating nonformulary requests.

Our findings underscore the need for an ongoing dialogue between physicians and pharmacists, so that they may reconcile their distinct views about nonformulary medications and work in an integrated way to provide patient care. Because of their role on the P\&T committee, the physicians in this study likely appreciated the perspective of their pharmacy peers better than the average physician. Nevertheless, physicians still disagreed with pharmacists about key issues. Managing these differing views at both the local and national levels is important to ensure that P\&T committees benefit from this diversity of opinion, rather than fall victim to misunderstandings between different provider types. These lessons likely hold true not only for VA, but also for other health systems that manage a uniform formulary or are planning to develop one.

\section{Limitations}

Our study has important limitations. First, in order to maintain anonymity in our survey, we were unaware of the characteristics of our respondents and those who did not reply. We therefore cannot examine nonrespondents to know if any response biases may be present. Second, although this study demonstrates that significant differences exist between VAMCs regarding their formulary utilization management approaches, it does not link these differences directly to variation in the use of expensive nonformulary medications previously reported. ${ }^{15-17}$ Further research is required to compare variations in drug utilization management practices with differences in drug spending and prescribing, including use of brandname medications.

\section{Conclusions}

Although implementation and management of a national formulary have enabled VA to save billions of dollars and improve patient safety for veterans ${ }^{10}$ variations between VAMCs regarding the use of nonformulary drugs still exist. ${ }^{15-17}$ This study highlights the differences in the implementation of formulary policies that may impact variation in drug use. Other health care systems that seek to improve the uniformity, appropriateness, and cost-effectiveness of their drug benefit should examine variations in the application of their pharmacy benefit.

\section{Authors}

THOMAS R. RADOMSKI, MD, is Clinical Instructor, Division of General Internal Medicine, Department of Medicine, University of Pittsburgh School of Medicine, and Clinical Research Fellow, Center for Health Equity Research and Promotion, VA Pittsburgh Healthcare System, Pittsburgh, Pennsylvania. CHESTER B. GOOD, $\mathrm{MD}, \mathrm{MPH}$, is Professor, Division of General Internal Medicine, Department of Medicine, University of Pittsburgh School of Medicine; Professor, Department of Pharmacy and Therapeutics, University of Pittsburgh School of Pharmacy; Core Investigator, Center for Health Equity Research and Promotion, VA Pittsburgh Healthcare System, Pittsburgh, Pennsylvania; and Chair, Medical Advisory Panel, and Co-director, VA Center for Medication Safety, Pharmacy Benefits Management Services, U.S. Department of Veterans Affairs, Hines, Illinois. CAROLYN T. THORPE, PhD, MPH, is Core Investigator, Center for Health Equity Research and Promotion, VA Pittsburgh Healthcare System, Pittsburgh, Pennsylvania, and Assistant Professor, Department of Pharmacy and Therapeutics, University of Pittsburgh School of Pharmacy, Pittsburgh, Pennsylvania. XINHUA ZHAO, PhD, is Statistician, Center for Health Equity Research and Promotion, VA Pittsburgh Healthcare System, Pittsburgh, Pennsylvania, and ZACHARY A. MARCUM, PharmD, PhD, is Assistant Professor, Division of Geriatric Medicine, Department of Medicine, University of Pittsburgh School of Medicine, Pittsburgh, Pennsylvania. PETER A. GLASSMAN, MBBS, is Staff Physician, VA Greater Los Angeles Healthcare System; Professor of Clinical Medicine, Department of Medicine, David Geffen School of Medicine, University of California, Los Angeles; and Chair, Medical Advisory Panel, and Co-director, VA Center for Medication Safety, Pharmacy Benefits Management Services, U.S. Department of Veterans Affairs, Hines, Illinois. JOHN LOWE, MBA, is Associate Chief Consultant, Pharmacy Compliance and Efficiency, Pharmacy Benefits Management Services, U.S. Department of Veterans Affairs, Hines, Illinois. MARIA K. MOR, PhD, is Director, Biostatistics and Informatics Core, Center for Health Equity Research and Promotion, VA Pittsburgh Healthcare System, and Research Assistant Professor, Department of Biostatistics, University of Pittsburgh, Pittsburgh, Pennsylvania. MICHAEL J. FINE, MD, MSc, is Professor, Division of General Internal Medicine, Department of Medicine, University of Pittsburgh School of Medicine, and Director, Center for Health Equity Research and Promotion, VA Pittsburgh Healthcare System, Pittsburgh, Pennsylvania. WALID F. GELLAD, $\mathrm{MD}, \mathrm{MPH}$, is Associate Professor, Division of General Internal Medicine, Department of Medicine, University of Pittsburgh School of Medicine, and Core Investigator, Center for Health Equity Research and Promotion, VA Pittsburgh Healthcare System, Pittsburgh, Pennsylvania.

AUTHOR CORRESPONDENCE: Walid F. Gellad, MD, MPH, Center for Health Equity Research and Promotion, VA Pittsburgh Healthcare System, University Dr., 151C, Pittsburgh, PA 15240. Tel.: 412.360.2267; Fax: 412.360.2284; E-mail: walid.gellad@va.gov.

\section{DISCLOSURES}

Radomski is funded by a Health Resources and Services Administration T32 Training Grant. Gellad is funded by a VA HSR\&D Career Development Award. The authors have no other conflicts of interest to disclose. 
Study design was created by Good, Marcum, Lowe, and Gellad, with assistance from Glassman. Zhao, Mor, and Gellad collected the data, assisted by Good, Lowe, and Marcum, and data interpretation was performed by Radomski, Mor, Zhao, and Gellad, with assistance from the other authors. The manuscript was written primarily by Radomski, along with Gellad, with assistance from Mor and Fine. The manuscript was revised primarily by Thorpe, Glassman, and Fine, with input from the other authors.

\section{ACKNOWLEDGMENTS}

The authors would like to thank Galen Switzer, PhD, for his contributions to the design of the survey.

\section{REFERENCES}

1. Hoodly J. Cost containment strategies for prescription drugs: assessing the evidence in the literature. The Kaiser Family Foundation. March 2005. Available at: http://kff.org/medicaid/report/cost-containment-strategies-forprescription-drugs-assessing/. Accessed November 13, 2015.

2. Foulke GE, Siepler J. Antiulcer therapy: an exercise in formulary management. J Clin Gastroenterol. 1990;12(Suppl 2):S64-68.

3. Ganz MB, Saksa B. Switching long-acting nifedipine. Fed Pract. 1997;14(5):71.

4. Gustin G, White WB, Taylor S, Daragjati C. Clinical outcome of a mandatory formulary switch for dihydropyridine calcium channel blocker therapy at a Veteran's Administration Medical Center. Am J Hypertens. 1996;9(4 Pt 1): 312-16.

5. Block LC, Dearing CJ, Briscoe TA, Morgan SM. Clinical and economic outcomes of a nifedipine-to-felodipine switch program. Formulary. 1998;33(5):448-54

6. Lederle FA, Rogers EM. Lowering the cost of lowering the cholesterol: a formulary policy for lovastatin. J Gen Intern Med. 1990;5(6):459-63. Available at: http://link.springer.com/article/10.1007/BF02600868\#. Accessed November 13, 2015.

7. Rindone JP, Arriola G. Conversion from fluvastatin to simvastatin therapy at a dose ratio of 8 to 1: effect on serum lipid levels and cost. Clin Ther. 1998;20(2):340-46.

8. DiLiegro N, Groves AJ, Caspi A. Cost-containment perspectives: cost savings from an antimicrobial-monitoring program. P \& T. 1998;23:419-24.

9. Smalley WE, Griffin MR, Fought RL, Sullivan L, Ray WA. Effect of a prior-authorization requirement on the use of nonsteroidal antiinflammatory drugs by Medicaid patients. N Engl J Med. 1995;332(24):1612-17. Available at: http://www.nejm.org/doi/full/10.1056/NEJM199506153322406. Accessed November 13, 2015.

10. Sales MM, Cunningham FE, Glassman PA, Valentino MA, Good CB. Pharmacy benefits management in the Veterans Health Administration: 1995 to 2003. Am J Manag Care. 2005;11(2):104-12.

11. Good CB, Valentino M. Access to affordable medications: the Department of Veterans Affairs pharmacy plan as a national model. Am J Public Health. 2007;97(12):2129-31. Available at: http://www.ncbi.nlm.nih. gov/pmc/articles/PMC2089089/. Accessed November 13, 2015.

12. Patel RJ, Gray DR, Pierce R, Jafari M. Impact of therapeutic interchange from pravastatin to lovastatin in a Veterans Affairs Medical Center. Am J Manag Care. 1999;5(4):465-74.
13. Coté GA, Ferreira MR, Rozenberg-Ben-Dror K, Howden CW. Programme of stepping down from twice daily proton pump inhibitor therapy for symptomatic gastro-oesophageal reflux disease associated with a formulary change at a VA medical center. Aliment Pharm Therap. 2007;25(6):709-14. Available at: http://onlinelibrary.wiley.com/doi/10.1111/j.13652036.2007.03248.x/abstract. Accessed November 13, 2015.

14. Aspinall SE, Zhao X, Good CB, Stone RA, Smith KJ, Cunningham FE. FDA warning and removal of rosiglitazone from VA national formulary. Am J Manag Care. 2013;19(9):748-58. Available at: http://www.ajmc.com/ publications/issue/2013/2013-1-vol19-n9/fda-warning-and-removal-of-rosiglitazone-from-va-national-formulary. Accessed November 13, 2015.

15. Gellad WF, Good CB, Lowe JC, Donohue JM. Variation in prescription use and spending for lipid-lowering and diabetes medications in the VA Healthcare System. Am J Manag Care. 2010;16(10):741-50. Available at: http://www.ncbi. nlm.nih.gov/pmc/articles/PMC3096004/. Accessed November 19, 2015.

16. Gellad W, Mor M, Zhao X, Donohue J, Good C. Variation in use of highcost diabetes mellitus medications in the VA healthcare system. Arch Intern Med. 2012;172(20):1608-09. Available at: http://archinte.jamanetwork.com/ article.aspx?articleID=1377416. Accessed November 13, 2015.

17. Gellad WF, Donohue JM, Zhao X, et al. Brand-name prescription drug use among Veterans Affairs and Medicare Part D patients with diabetes: a national cohort comparison. Ann Intern Med. 2013;159(2):105-14. Available at: http:// annals.org/article.aspx?articleid=1709824. Accessed November 19, 2015.

18. Lund BC, Bernardy NC, Vaughan-Sarrazin M, Alexander B, Friedman MJ. Patient and facility characteristics associated with benzodiazepine prescribing for veterans with PTSD. Psychiatr Serv. 2013;64(2):149-55. Available at: http://journals.psychiatryonline.org/article. aspx?articleid=1392114. Accessed November 13, 2015.

19. Lund BC, Charlton ME, Steinman MA, Kaboli PJ. Regional differences in prescribing quality among elder veterans and the impact of rural residence. J Rural Health. 2013;29(2):172-9. Available at: http://onlinelibrary.wiley.com/ doi/10.1111/j.1748-0361.2012.00428.x/full. Accessed November 13, 2015.

20. Veterans Health Administration. VHA formulary management process. VHA Handbook 1108.08. February 26, 2009. Available at: http://www.pbm. va.gov/directive/vhadirective.pdf. Accessed November 13, 2015.

21. Rucker TD, Schiff G. Drug formularies: myths-in-formation. Med Care. 1990;28(10):928-42.

22. Schiff GD, Galanter WL, Duhig J, et al. A prescription for improving drug formulary decision making. PLoS Medicine. 2012;9(5):e1001220. Available at: http://www.plosmedicine.org/article/info\%3Adoi\%2 F10.1371\%2Fjournal.pmed.1001220. Accessed November 13, 2015.

23. Duffy SW, Rohan TE, Altman DG. A method for combining matched and unmatched binary data. Application to randomized, controlled trials of photocoagulation in the treatment of diabetic retinopathy. Am J Epidemiol. 1989;130(2):371-78. Available at: http://aje.oxfordjournals.org/ content/130/2/371.short. Accessed November 13, 2015.

24. Glassman PA, Good CB, Kelley ME, et al. Physican perceptions of a national formulary. Am J Manag Care. 2001;7(3):241-51.

25. Robberecht R, Cardoen B, Gemmel P. Breaking down the silo of the hospital pharmacy. Br J Hosp Med. 2014;75(9):486-487. Available at: http:// ke7lm8xu6w.scholar.serialssolutions. com/?sid=google \&auinit=B\&aulast=Ca rdoen \&atitle=Breaking + down + the + silo + of + the + hospital + pharmacy. $\&$ id $=$ pm id:25216162. Accessed November 13, 2015.

26. Vichiendilokkul A. Breaking out of the silo: one health system's experience. Am J Health Syst Pharm. 2002;59(6):S15-17. 


\section{APPENDIX Survey Questions Addressed in the Results Section}

\section{Criteria for Use}

Does your Medical Center routinely use national PBM Criteria For Use (CFU) in assessing non-formulary drug requests?

$\square$ Yes $\square$ No $\square$ Unsure

How would you rate your VA Medical Center's level of adherence to the VA CFU? (Please check one response):

$\square$ Very adherent (Follows the "letter of the law" literally)

$\square$ Mostly adherent (Follows most CFU according to specifications)

Somewhat adherent (Meets the general intent of CFU)

Are national CFU ever modified for local use (other than formatting changes) at your Medical Center?

$\square$ Yes $\square$ No $\square$ Unsure

How frequently do you modify (other than formatting changes) national CFU for local use? (Please check one response)

$\square$ Rarely (1-2 times/year) $\square$ Sometimes (3-10 times/year) $\square$ Often (> 10 times/year)

For medications where national CFU are not available, how frequently are local CFU developed at your Medical Center/VISN? (Please check one response)

$\square$ Never $\square$ Rarely $\square$ Sometimes $\square$ Often $\square$ Always

Specific Procedures

Are decisions about non-formulary drug requests primarily made at the VISN or VA Medical Center level?

$\square$ VISN level $\square$ VA Medical Center level

How are pharmacists assigned to review non-formulary drug requests? (Please check ALL THAT APPLY)

$\square$ By drug class (e.g., cardiovascular, HIV, oncology)

$\square$ By primary care clinic(s) (e.g., Blue Clinic, Red Clinic, etc.)

$\square$ By specialty clinic(s) (e.g., Renal Clinic, Neuro Clinic, etc.)

$\square$ No specific assignment

$\square$ Other (please specify)

For non-formulary drug requests requiring additional clinical/cost considerations, who else is/are involved in the decision-making process? (Please check ALL THAT APPLY)

$\square$ Chief/Assistant Chief of Pharmacy

$\square$ Chief/Assistant Chief of Staff

$\square$ One designated pharmacist

$\square$ One pharmacist among a group of pharmacists

$\square$ P\&T Committee or a P\&T designated clinician(s)

$\square$ Other (please specify, but do not list person's name)

At your VA Medical Center, are non-formulary lipid-lowering agents (ezetimibe, atorvastatin, rosuvastatin) and thiazolidinediones (pioglitazone) viewable by providers in the normal CPRS medication order entry screen (that is, the screen where providers type in medication names)? (Please check one response for each drug)

\begin{tabular}{|l|l|l|l|l|}
\hline & Ezetimibe & Atorvastatin & Rosuvastatin & Pioglitazone \\
\hline Viewable by providers & & & & \\
\hline NOT viewable by providers & & & & \\
\hline Uncertain & & & & \\
\hline
\end{tabular}

Appeals Process

Using your best estimate, what percentage of non-formulary requests are denied at your facility? $\%$

Using your best estimate, what percentage of denied non-formulary requests are appealed at your facility? $\%$

If a non-formulary request decision is appealed by a provider, who is typically responsible for deciding if the decision should be overturned? (Please check all that apply)

$\square$ Chief/Assistant Chief of Pharmacy

$\square$ Chief/Assistant Chief of Staff

$\square$ P\&T Committee or a P\&T designated clinician(s)

$\square$ Other (please specify, but do not list person's name)

Depends on the specific drug 


\section{APPENDIX Survey Questions Addressed in the Results Section (continued)}

Formulary Environment

*Responses to all of the following questions were based on a 5 point Likert Scale:

$\square$ Strongly agree $\square$ Agree $\square$ Neutral $\square$ Disagree $\square$ Strongly disagree

It is important that providers prescribe VA formulary medications before making non-formulary requests (assuming contraindications to the formulary medication do not exist)

The non-formulary approval process is effective in controlling drug costs at your VA Medical Center.

Your VA Medical Center has a local champion or opinion leader for cost-effective drug utilization.

The non-formulary approval process is effective in ensuring quality of care and/or safety of drug use at your VA Medical Center.

There is a lot of variation in approval rates among those who review and decide on non-formulary requests at your VA Medical Center.

Providers at your VA Medical Center prescribe too many non-formulary drugs (i.e., more than clinically indicated in the setting of the VA formulary).

Non-formulary restrictions make providers jump through too many hoops to provide high-quality patient care.

For new patients who come to your VA Medical Center already receiving non-formulary lipid-lowering medications, providers usually make an effort to switch the patient to a formulary medication (if not contraindicated) prior to request of any non-formulary agents.

For new patients who come to your VA Medical Center already receiving non-formulary thiazolidinediones, providers usually make an effort to switch the patient to a formulary medication (if not contraindicated) prior to request of any non-formulary agents. 